\title{
An Empirical Study on the Influencing Factors of College Students' Privacy Concern
}

\author{
Yu Peng \\ School of Public Administration, China University of Mining and Technology, \\ No. 1, Daxue Road, Xuzhou City, Jiangsu Province, China
}

\begin{abstract}
In recent years, privacy issues have attracted more and more attention. This paper combines existing research and the CFIP scale to construct a model of college students' concerns about Internet privacy, and validates the model based on data from 445 questionnaires. The results show that perceived privacy risks, privacy control, privacy tendencies, misrepresentation, improper access, and unauthorized secondary use all have a significant impact on privacy concerns, and environmental factors have a more significant impact on privacy concerns. On this basis, relevant suggestions are provided.
\end{abstract}

Keywords: College students, Privacy concerns, CFIP, Influencing factors.

\section{Introduction}

In recent years, the brutal growth and widespread use of big data technology has also spawned problems such as the proliferation of false data, the spread of information alienation, and the widening of the data gap, especially the "traces left by people in social networks, smart life, online transactions, etc." "The excessive tracking and permanent memory of big data technology has caused the public's private information to be continuously leaked or abused in applications such as data sharing, mining, forecasting, and monitoring. Individuals gradually lose control of their own information, causing them the protection of citizens' privacy has fallen into an ethical dilemma. The college student group is a group of young and high-quality adolescents in China. Research on college students who have grown up in the digital environment of the Internet is important for how to regulate and guide the technological development of the new digital age and handle the relationship between information access and privacy protection.

The social sciences are paying more and more attention to privacy and privacy concerns, and there have been many empirical studies based on the influencing factors of privacy concerns. Models such as CFIP [1], IUICP [2], and MUICP [3] have been constructed. However, most research treat the concept of privacy concerns as general concerns, which only reflect personal concerns about possible loss of private information [2]. However, he did not notice that privacy may be more specific to a certain situation [4] rather than character or traits.

In order to make up for the deficiencies of previous research, this research adds the concept of privacy concerns to the specific context that it applies to, that is, consumers' concerns about the potential loss of privacy caused by disclosure of information to specific external agency websites. The new concept emphasizes two aspects, one is the inherent characteristics of Internet users, and the other is the Internet platform environment in which they are located.

\section{Literature Review}

Privacy concern is a series of special information awareness and perception related to privacy leakage [5]. The definition of privacy concern mostly starts from the subjective feelings of individuals [6]. The earlier definition is that after the data is provided to the organization, individuals have concerns about how the organization uses their own data. With the development of the Internet, the definition of privacy concerns is constantly evolving. In the Internet age, privacy concerns about the collection, control, and use of information submitted to Internet platforms. In recent years, domestic scholars have also begun to conduct various related studies around privacy concerns. Wang Lixian researches how users' information on shopping websites is used after being obtained by others. Privacy concerns have an adverse effect on the continued use of social networks and constitute costs related to privacy. The privacy paradox of inconsistency between human behavior and the Internet [6]. The user is in a competitive benefit situation and possible wind The privacy calculation behavior of the trade-off between risk results.

Scholars have different opinions on the composition of privacy concerns. The most representative ones are the CFIP and IUIPC scales. CFIP divides privacy concerns into four categories, namely collection, inappropriate access, unauthorized secondary use, and errors, to measure the individual's concern about the organization's privacy behavior [1]. And IUIPC measures privacy concerns in the Internet environment, including three dimensions of collection, control, and awareness [2].

With increasing attention to privacy issues, researchers in the social sciences have also made many empirical studies on "privacy concerns". Because privacy itself is difficult to measure, many empirical studies in the field of information privacy are based on the measurement of privacy concerns. The academic community has also developed various privacy concern scales to meet different needs, such as Table 1 Privacy Concerns Existing Research 
Table 1: Privacy Concerns Existing Research

$\begin{array}{ccc}\text { Scale } & \text { Time } & \begin{array}{c}\text { Factor } \\ \text { CFIP }\end{array} \\ \text { Collection, error, unauthorized secondary use, } \\ \text { improper access } \\ \text { CFIP } & 2002 & \begin{array}{c}\text { Collection, unauthorized secondary use, } \\ \text { improper access and errors, computer anxiety, } \\ \text { behavioral intentions } \\ \text { Collection, control, awareness }\end{array} \\ \text { IUIPC } & 2004 & \begin{array}{c}\text { Image difference, decision control, social } \\ \text { network overlap }\end{array} \\ \text { IPCPD } & 2015 & \begin{array}{c}\text { Perceived severity, perceived vulnerability, } \\ \text { response efficiency, reward, self-efficacy } \\ \text { Computer anxiety, perception control, } \\ \text { application permission issues, previous privacy } \\ \text { experience }\end{array} \\ \text { MUIPC } & 2018 & \text { 2020 }\end{array}$

Therefore, this study will be combined with the CIFP scale on top of Heng $\mathrm{Xu}$ et al.'s scale [3]. Fully consider the influencing factors of personal characteristics and platform environment and form a new privacy concern scale with six factors such as perceived privacy risk, privacy control, emphasis on privacy tendency, misrepresentation, improper access, and unauthorized secondary use.

\section{Research Model}

We first divide the influencing factors of privacy concerns into two parts, the user's personal characteristics and platform factors. We first propose this new factor focus model, and then describe the source basis of each factor in the model, as well as the assumptions we made before the study.

\subsection{Perceived Privacy Risks}

Risk is often defined as the uncertainty caused by potentially causing its own losses [6] and its possible negative results [5]. Jarvenpaa's research has confirmed that perceived risk has a negative impact on trading. We define risk as the expected loss related to the disclosure of personal information. Perceived privacy risk is regarded as a negative antecedent factor, which is expected to affect a person's attitude, which is learned in human practice. Previous empirical research also supports the correlation between risk perception and privacy issues. Due to the high risk of disclosing personal information, individuals will have concerns about this private information. That is, increase privacy concerns. Therefore, the following assumptions are drawn:

H1: Perceived privacy risks have a positive impact on privacy concerns.

\subsection{Privacy Control}

In most cases, privacy control is not well separated from privacy. In fact, users have the ability to control private information, that is, control over who can obtain their own information, control how the information will be used, and control the extent to which the Internet platform can obtain it. The information has an important impact on users' privacy concerns. Dinev's research in 2004 showed that privacy information control is one of the key factors explaining privacy concerns. These previous studies have proved that privacy control should be clearly separated from privacy and act as an independent influencing factor to affect privacy concerns. Generally speaking, when individuals are more consciously controlling the release and dissemination of personal information, their privacy concerns will be less, and vice versa, they will have more concerns and worries about privacy. In other words, we think:

H2: Privacy control has a negative impact on privacy concerns.

\subsection{Value Privacy}

Paying attention to privacy is a personality attribute that reflects the inherent needs of individuals to maintain the personal information space and its boundaries. In addition, some scholars have defined it as: a person's general tendency to maintain his private information space or restrict the disclosure of personal information under a wide range of circumstances and backgrounds. It also proves that the personal preference for privacy will determine the opening and closing rules of the communication boundary [3]. Individuals with higher personal privacy tendencies are more likely to regard convenient penetration as an intrusion, so they are worried about their privacy, and tend to pay more attention to privacy. Individuals with low levels may not view the same penetration as a privacy intrusion. Therefore, we also have sufficient reasons to draw the following assumptions:

H3: Attaching importance to privacy tends to positively affect privacy concerns.

\subsection{Wrong Presentation}

Misrepresentation is an error of personal information caused by subjective or objective factors on the Internet platform. Although many issues may be subjective, most privacy-related issues are accidental errors in the design of personal data. With the advancement of technology, people have begun to set up procedures to check and correct this kind of data, but the error-producing situation is still common. Studies have found that the internal system of the Internet platform may not function properly, causing personal data errors. These erroneous data may lead to erroneous bills, erroneous transportation and other negative results, thereby increasing users' privacy concerns and concerns. Therefore, we assume:

H4: Misrepresentation positively affects privacy concerns.

\subsection{Improper Access}

There is no clear definition of who has the right to obtain information and who does not have the right to obtain information from users, but it is also a matter of great concern to users. The lack of security of the merchant system may lead to security violations and unauthorized access, which may lead to identity theft, privacy exposure, fraud and other consequences. At the same time, Internet security weaknesses, hackers and other threats to Internet security, may also cause people's anxiety about the information they submit to the platform, thereby increasing privacy concerns. Thus, we can 
assume:

H5: Improper access positively affects privacy concerns.

\subsection{Unauthorized Secondary Use}

Unauthorized secondary use refers to a situation where our information is sometimes collected from individuals for one purpose but is used for another secondary purpose without the user's personal authorization [1]. It can be seen that unauthorized use of user information can also cause negative reactions. China also promulgated related "crimes of selling or illegally providing citizens' information" in 2009. It can be seen that unauthorized secondary use poses a threat to users' privacy, thereby affecting users' privacy concerns. Therefore, assume the following:

H6: Unauthorized secondary use positively affects privacy concerns.

\section{Research Method}

\subsection{Questionnaire Design and Data Collection}

The questionnaire is divided into two parts: one is the demographic characteristics, and the other is the privacy concerns of college students on the Internet. That is, the measurement of various possible factors that affect college students' Internet privacy concerns, as shown in Table 4. All items are derived from existing research results.

Table 4: Dimension, Item and Reference

\begin{tabular}{|c|c|c|c|c|c|c|}
\hline & Dimension & Factor & Item & $\alpha$ & $\begin{array}{c}\text { Factor } \\
\text { Analysis }\end{array}$ & Reference \\
\hline \multirow[t]{9}{*}{$\begin{array}{l}\text { Personal } \\
\text { Qualities }\end{array}$} & $\begin{array}{l}\text { Perceived } \\
\text { privacy } \\
\text { risks }\end{array}$ & RK1 & Generally speaking, providing personal information to the website is risky. & 0.88 & 0.883 & $\begin{array}{c}\text { Heng } \\
\mathrm{Xu}, 2011\end{array}$ \\
\hline & & RK2 & Providing my information to the website is likely to cause loss of privacy. & & 0.858 & \\
\hline & & RK3 & My personal information may be used improperly by the website. & & 0.842 & \\
\hline & \multirow{3}{*}{$\begin{array}{l}\text { Privacy } \\
\text { control }\end{array}$} & PL1 & $\begin{array}{c}\text { I believe that I can control how my information is collected, used, developed } \\
\text { and shared. }\end{array}$ & \multirow{3}{*}{0.86} & 0.864 & \\
\hline & & PL2 & $\begin{array}{c}\text { I believe I can control which of my personal information is provided to this } \\
\text { website. }\end{array}$ & & 0.879 & \\
\hline & & PL3 & I believe I can control who will get my personal information & & 0.870 & \\
\hline & \multirow{3}{*}{$\begin{array}{l}\text { Value } \\
\text { privacy }\end{array}$} & DP1 & $\begin{array}{l}\text { Compared with others, I am more sensitive to the way the company handles } \\
\text { my personal information. }\end{array}$ & \multirow{3}{*}{0.83} & 0.796 & \\
\hline & & DP2 & $\begin{array}{c}\text { Compared with others, I am more worried about threats to information } \\
\text { privacy }\end{array}$ & & 0.849 & \\
\hline & & DP3 & $\begin{array}{c}\text { To me, maintaining the privacy of my information is the most important } \\
\text { thing. }\end{array}$ & & 0.737 & \\
\hline \multirow[t]{9}{*}{$\begin{array}{c}\text { Platform } \\
\text { factors }\end{array}$} & \multirow[t]{3}{*}{ Error } & ER1 & $\begin{array}{l}\text { The network platform should take more measures to ensure that the } \\
\text { information in the archive is accurate }\end{array}$ & 0.8 & 0.746 & CIFP \\
\hline & & ER2 & $\begin{array}{c}\text { Network platforms should have better procedures to correct errors in } \\
\text { personal information }\end{array}$ & & 0.792 & \\
\hline & & ER3 & $\begin{array}{l}\text { The network platform should spend more time and experience to verify the } \\
\text { accuracy of the information in the database }\end{array}$ & & 0.782 & \\
\hline & \multirow{3}{*}{$\begin{array}{l}\text { Improper } \\
\text { access }\end{array}$} & IA1 & $\begin{array}{l}\text { Network platforms should take more measures to prevent hackers from } \\
\text { attacking }\end{array}$ & \multirow{3}{*}{0.822} & 0.884 & \\
\hline & & IA2 & $\begin{array}{c}\text { Online platforms should take more measures to ensure compliance with } \\
\text { relevant privacy and promote data protection legislation }\end{array}$ & & 0.790 & \\
\hline & & IA3 & $\begin{array}{l}\text { The network platform should devote more time and effort to prevent } \\
\text { unauthorized units or individuals from accessing users' personal information }\end{array}$ & & 0.886 & \\
\hline & \multirow{3}{*}{$\begin{array}{l}\text { Secondary } \\
\text { use }\end{array}$} & US1 & $\begin{array}{l}\text { I am worried that the online platform will use the private information I } \\
\text { submitted }\end{array}$ & \multirow{3}{*}{0.83} & 0.937 & \\
\hline & & US2 & $\begin{array}{l}\text { I am worried that the personal information submitted on the online platform } \\
\text { will be used in a way that I did not foresee }\end{array}$ & & 0.832 & \\
\hline & & US3 & $\begin{array}{l}\text { Online platforms should not sell my personal information to other } \\
\text { companies. }\end{array}$ & & 0.803 & \\
\hline
\end{tabular}

The subjects of the survey are Internet users in China University of Mining and Technology. The investigation period is from December 282020 to January 20 2021. A total of 454 questionnaires were received. Invalid questionnaires such as blanks and all items selected the same item were excluded, leaving 445 valid questionnaires.

\subsection{Data Analysis}

\subsubsection{Frequency Analysis of Demographic Variables}

According to the analysis results in Table 1, the numerical characteristics of demographic variables can be seen. Reflects the distribution of the surveyed objects this time. The mean value represents the central tendency. The standard deviation represents the volatility.

According to the frequency analysis results of each variable, it can be seen that the distribution basically meets the requirements of the sampling survey. For example, the gender survey results show that the proportion of men is $52 \%$ and the proportion of women is $43 \%$. The gender ratio is basically balanced, reflecting a good sampling situation and strong sample representativeness.

\subsubsection{Reliability and validity analysis}

According to Table 2, the value range of the reliability coefficient is between $0-1$, and the closer to 1 the higher the reliability. The Cronbach's Alpha values of several 
dimensions of this questionnaire are all greater than 0.75 , which is relatively reliable. It shows that the data of the scale has high reliability and can be further analyzed.

Table 2: Frequency analysis of demographic variables

\begin{tabular}{ccccc}
\hline Item & Frequency & Percentage & Average & $\begin{array}{c}\text { Standard } \\
\text { Deviation }\end{array}$ \\
\hline Male & 242 & $52 \%$ & 1.46 & 0.50 \\
Female & 202 & $43 \%$ & 1.50 \\
\hline
\end{tabular}

Exploratory factor analysis is generally used for testing. According to the calculated results, as shown in Table 3, the KMO value of the scale is 0.779 and the significance $p$ value is 0.000 . Since the KMO value is above 0.7, the Bartlett sphere test also reaches the significance level, indicating that there are common factors between the items. Do exploratory factor analysis on sample data.

In this paper, through principal component analysis, the maximum variance method is used to extract 18 common factors in the scale. According to the results in Table 4, it can be seen that the load of each item in the scale is greater than 0.7 , indicating that the questionnaire has a good structure. Validity. Based on this, this scale has good reliability and validity and can be analyzed in the next step.

Table 3: Validity analysis result

\begin{tabular}{cccc}
\hline KMO & \multicolumn{2}{c}{ Bartlett's sphericity test } & \\
& $\begin{array}{c}\text { Approximate } \\
\text { chi-square }\end{array}$ & df & Sig. \\
\hline 0.779 & 4744.519 & 210 & .00 \\
\hline
\end{tabular}

\section{Research Results and Discussion}

The study uses multiple regression analysis, and the results are in Figure 1. The purpose of this research is to explore the privacy concerns of college students on the Internet and the factors that affect their privacy concerns. Specifically, there are two: The first is to study the factors affecting the privacy concerns of college students on the Internet, that is, whether the six previously assumed factors have an impact on privacy concerns. The second is that this research has transformed the traditional user's intrinsic characteristics that affect privacy concerns into a comprehensive study of the internal and external environments of privacy concerns, that is, the influence of personal characteristics and platform environmental factors on privacy concerns.

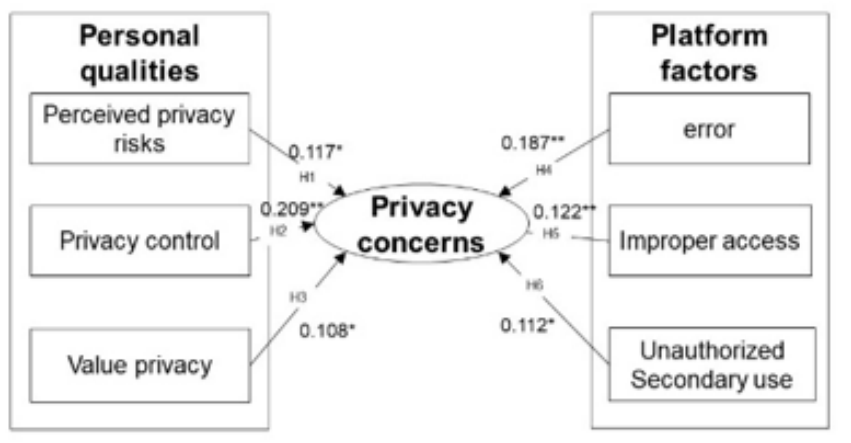

Figure 1: Standardized path coefficient

The conclusions after analysis using SPSS24.0 are as follows:

First, the six previously assumed factors all have a significant impact on the privacy concerns of college students. Among them, privacy control has the most significant impact on it, indicating that college students generally believe that the strength of privacy control will directly affect the degree of privacy concerns. When people clearly give Internet users the opportunity to opt out of the information they provide to the Internet platform, their privacy concerns will be reduced. Therefore, for college Internet users, users generally hope to have the ability to control personal information. The next influencing factor is error presentation, that is, errors caused by the imperfection of the Internet platform and the abnormal operation of its internal system will strongly affect the privacy concerns of users. The third is improper access, that is, Internet users of college students are concerned about who can obtain their private information, the degree of security of the platform built on the Internet, and the degree of security of the entire Internet environment. If the privacy data submitted by users cannot be well protected, users' privacy concerns will be increased.

Second, overall, the external platform environment has a significant impact on privacy concerns. The significance of the three factors describing the external platform environment is among the first few of all six factors. Therefore, it can be explained that the current Internet privacy concerns of our college students are not only the traditional users' own control of their own private information, the perceived risk when providing information, and the importance of their own private information, but more on the Internet platform. Distrust and unknown. How will the Internet platform use my information, whether it will leak the information, whether the information provided to the Internet will be changed, and whether information errors will be corrected by setting procedures. This research shows that the influence of these external platform environmental factors on college students' concerns about Internet privacy is more significant than the preference of Internet users' internal characteristics.

\section{Suggestions}

Based on the above research conclusions, the following suggestions are made for relevant Internet platform stakeholders:

1) Internet users of college students. Because of the inherent characteristics of users, their privacy concerns will be affected. Therefore, users should understand privacy risks, attach importance to privacy, and control the relevant privacy information they submit to the Internet. For example, carefully read the privacy protection guidelines in the Internet software, understand the relevant laws and policies, and prudently give the Internet platform its own privacy and authority; at the same time, college student Internet users should be more sensible in self-disclosure, facing some pirated websites, unfamiliar links, when dangerous web pages are not easy to fill in personal information, enhance the ability to distinguish dangerous and risky environments.

2) Internet platform. On the one hand, Internet platforms should abide by laws, regulations and moral bottom lines, and strictly abide by relevant privacy policies. Unsubjectively and 
deliberately disclose user information, do not trade or misappropriate users' private information. On the other hand, improve platform construction, protect related privacy information submitted by users, and strictly enforce the collection, storage and error correction process of user privacy information to reduce errors in user privacy information. Strengthen technical construction to prevent hackers and criminals from threats to users' private information. With all the rights to resources, Internet platforms can limit the content released by the media and reduce the risk of uneven commercial information dissemination.

3) Government departments. As the Internet is mixed, the mixed information is also mixed, and the privacy of users is basically half-naked. Government departments can strengthen the regulation of the degree of privacy protection of Internet platforms, punish platforms that arbitrarily leak user privacy, and promote safer privacy protection methods. At the same time, it can also strengthen the formulation of laws and regulations and accelerate the formulation of more standardized privacy protection laws.

\section{References}

[1] Smith, Jeff H, Milberg, et al. Information Privacy: Measuring Individuals' Concerns About Organizational Practices. [J]. MIS Quarterly, 1996.

[2] Malhotra N K, Kim S, Agarwal J. Internet users' information privacy concerns (IUIPC): The construct, the scale, and a causal model [J]. Information Systems research, 2004, 15(4): 336-355.

[3] Xu, Heng \& Gupta, Sumeet \& Rosson, Mary Beth \& Carroll, John. (2012). Measuring mobile users' concerns for information privacy. International Conference on Information Systems, ICIS 2012.3: 2278-2293.

[4] Stephen, T, Margulis. On the Status and Contribution of Westin's and Altman's Theories of Privacy[J]. Journal of Social Issues, 2003.

[5] Rifon N J, LaRose R, Choi S. Your privacy is sealed: Effects of Web privacy seals on trust and personal disclosures [J]. Journal of Consumer Affairs, 2005, 39(2): 339-362.

[6] Campbell A J. Relationship marketing in consumer markets: A comparison of managerial and consumer attitudes about information privacy [J]. Journal of Interactive Marketing, 1997, 11(3): 44-57. 